\section{Brain, Behavior and Evolution}

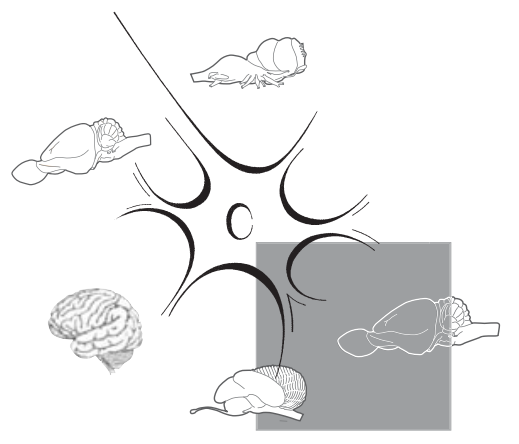

The 2 phases of the desert locust Schistocerca gregaria are very different beasts. Solitarious individuals are slow-moving, nocturnal and cryptically colored, avoiding contact with conspecifics except for mating. But when crowded, sensory stimulation from the jostling bodies causes these formerly retiring creatures to transform into a gregarious phase characterized by flashy aposematic coloration, high locomotor activity and active aggregation into day-flying swarms numbering hundreds of millions of individuals [Simpson et al., 1999, 2001; Anstey et al., 2001]. A new study by Ott and Rogers [2010] demonstrates that the brains of the 2 phases are as different as their behaviors, with gregarious individuals having brains 30\% larger than their solitarious counterparts. Within the brain, higher brain centers such as the mushroom bodies are disproportionally larger in gregarious locusts, while in solitarious locusts primary sensory neuropils such as the antennal lobes are larger. Solitarious individuals thus seem to be geared towards lower-level sensory processing, perhaps increasing their sensitivity to visual and odor cues. Gregarious individuals on the other hand prioritize higher integration, perhaps necessitated by their extremely generalist feeding ecology and the intense intraspecific interactions they experience within the gregarious swarm.

\title{
Locusts Provide Clues to Insect Mushroom Body Function
}

\author{
Sarah Farris \\ Department of Biology, Morgantown University, Morgantown, W. Va., USA
}

The insect mushroom bodies are sensory integration and learning and memory centers that display morphological plasticity on both individual and evolutionary timescales; mushroom bodies and their intrinsic neurons restructure in response to individual behavioral experience [Withers et al., 1993; Seid and Wehner, 2009], while across the insects particular mushroom body morphologies are linked to species-specific behavioral ecologies [Farris, 2005]. It is therefore not surprising to see significant differences in mushroom body morphology associated with the dramatic behavioral differences of gregarious and solitarious locusts. However, given the widely held belief that the mushroom bodies function predominantly as olfactory learning and memory centers [Davis, 2005], the disconnect between their size and that of the primary olfactory neuropils, the antennal lobes, seems somewhat anomalous. Rather, these results suggest that whatever functional demand the mushroom bodies of gregarious individuals have expanded to meet, it is unlikely to be solely associated with their role as olfactory processing centers.

Ott and Rogers suggest another challenge of life in the swarm that may impact mushroom body function: the need to extract salient sensory cues such as those produced by food sources and potential mates from the constant barrage of stimu- li produced by millions of other locusts. That the mushroom bodies may be involved in such sensory filtering is supported by recent studies in the fruit fly Drosophila melanogaster that implicate these brain centers in tasks related to feature extraction and the ability to fixate on salient stimuli when faced with distractors [Tang and Guo, 2001; Peng et al., 2007; Zhang et al., 2007]. More provocatively, the insect mushroom bodies have long been noted for their striking architectural similarity with vertebrate cerebellum-like structures [Li and Strausfeld, 1997; Laurent, 2002; Yasuyama et al., 2002], for which an emerging body of work suggests an underlying role as adaptive sensory filters [Bell et al., 2008; Dean et al., 2009]. If the mushroom bodies indeed play a role as sensory filters, they may be expected to be enlarged in species with lifestyles like that of the gregarious locust, in which extracting sensory signal from background noise approximates finding the proverbial needle in the haystack. Future comparative studies of mushroom body morphological variation in relation to species-specific processing demands will likely continue to shed light on the underlying functional role of these higher brain centers.

\section{KARGER}

Fax +4161306 1234 E-Mail karger@karger.ch www.karger.com
(C) 2011 S. Karger AG, Basel

0006-8977/11/0771-0003\$38.00/0

Accessible online at: www.karger.com/bbe
Sarah Farris

Department of Biology, Morgantown University

3139 Life Sciences Building, 53 Campus Drive, Morgantown, WV 26506 (USA)

Tel. +1 304293 5201, ext. 31528, Fax +1 3042936363

E-Mail Sarah.Farris@mail.wvu.edu 


\section{References}

Anstey ML, Rogers SM, Ott SR, Burrows M Simpson SJ (2009): Serotonin mediates behavioral gregarization underlying swarm formation in desert locusts. Science 323:627630.

Bell CC, Han V, Sawtell NB (2008): Cerebellumlike structures and their implications for cerebellar function. Annu Rev Neurosci 31:124.

Davis RL (2005): Olfactory memory formation in Drosophila: from molecular to systems neuroscience. Annu Rev Neurosci 28:275302.

Dean P, Porrill J, Ekerot C-F, Jörntell H (2009): The cerebellar microcircuit as an adaptive filter: experimental and computational evidence. Nat Rev Neurosci 11:30-43.

Farris SM (2005): Evolution of insect mushroom bodies: old clues, new insights. Arthropod Struct Dev 34:211-234.
Laurent G (2002): Olfactory network dynamics and the coding of multidimensional signals. Nat Rev Neurosci 3:884-895.

Li Y-S, Strausfeld NJ (1997): Morphology and sensory modality of mushroom body extrinsic neurons in the brain of the cockroach, Periplaneta americana. J Comp Neurol 387: 631-650.

Ott SR, Rogers SM (2010): Gregarious desert locusts have substantially larger brains with altered proportions compared with the solitarious phase. Proc R Soc B 277:3087-3096.

-Peng Y, Xi W, Zhang K, Guo A (2007): Experience improves feature extraction in Drosophila. J Neurosci 27:5139-5145.

Seid MA, Wehner R (2009): Delayed axonal pruning in the ant brain: a study of developmental trajectories. Dev Neurobiol 69:350364.

-Simpson SJ, Despland E, Hägele BF, Dodgson T (2001): Gregarious behavior in desert locusts is evoked by touching their back legs. Proc Nat Acad Sci 98:3895-3897.
Simpson SI, McCaffery AR, Hägele BF (1999): A behavioural analysis of phase change in the desert locust. Biol Rev 74:461-480.

Tang S, Guo A (2001): Choice behavior of Drosophila facing contradictory visual cues. Science 294:1543-1547.

Withers GS, Fahrbach SE, Robinson GE (1993): Selective neuroanatomical plasticity and division of labour in the honeybee. Nature 364: 238-240.

Yasuyama K, Meinertzhagen IA, Schürmann F-W (2002): Synaptic organization of the mushroom body calyx in Drosophila melanogaster. J Comp Neurol 445:211-226.

Zhang K, Guo JZ, Peng Y, Xi W, Guo A (2007): Dopamine-mushroom body circuit regulates saliency-based decision-making in Drosophila. Science 316:1901-1904. 